\author{
Małgorzata ŚLIWA ${ }^{1}$ \\ Justyna PATALAS-MALISZEWSKA ${ }^{2}$
}

\title{
MODEL DOBORU JEDNOSTKI BADAWCZO- ROZWOJOWEJ DLA PRZEDSIĘBIORSTWA OPARTEGO NA WIEDZY
}

\begin{abstract}
W gospodarce opartej na wiedzy przedsiębiorstwa dostrzegają potrzebę współpracy $\mathrm{z}$ jednostkami badawczo-rozwojowymi. Kulturę organizacyjną przedsiębiorstw mogą kształtować dynamika rynku, potrzeba doskonalenia i/lub wprowadzania innowacji (technologii, produktu) w celu rozwoju przedsiębiorstwa. Definicję kultury organizacyjnej w przedsiębiorstwie opartym na wiedzy przyjęto $w$ artykule na podstawie definicji kultury organizacyjnej według Jana Terelaka (2005) oraz Rafała Kuca i Joanny Moczydłowskiej (2009). Sformułowano ją jako przestrzeń w przedsiębiorstwie, która determinuje postawy pracowników w celu pozyskiwania oraz dzielenia się użyteczną wiedzą jawną i ukrytą w przedsiębiorstwie. W artykule dokonano próby wypracowania modelu doboru jednostki badawczorozwojowej dla przedsiębiorstwa opartego na wiedzy w celu podniesienia poziomu jego kultury organizacyjnej. Na podstawie analizy literatury przedmiotu zdefiniowano charakterystyki kultury organizacyjnej w przedsiębiorstwie opartym na wiedzy oraz określono parametry jednostki badawczo-rozwojowej. Mierniki definiujące powyższe zależności składają się z elementów tworzących kulturę obydwu instytucji, opisujących środowisko pracy oraz poziom zaawansowania technologicznego. Uwzględniono także czynniki wpływające na podział wiedzy oraz na pracownika i jego rozwój. Dzięki implementacji metody sieci Petriego (z ograniczoną pojemnością i liczbą miejsc) sformułowano model doboru jednostki badawczo-rozwojowej dla przedsiębiorstwa opartego na wiedzy. Implementacja opracowanego modelu pozwala na wsparcie procesu decyzyjnego w przedsiębiorstwie $\mathrm{w}$ aspekcie podjęcia współpracy z jednostką badawczo-rozwojową i realizacją wspólnego projektu badawczorozwojowego. Na podstawie własnych obserwacji zbudowano dwie współpracujące sieci Petriego, których implementacja pozwoli przedsiębiorstwu na osiągnięcie zdefiniowanych korzyści.

Słowa kluczowe: kultura organizacyjna, jednostki badawczo-rozwojowe, wiedza jawna, wiedza ukryta
\end{abstract}

\section{WPROWADZENIE}

W gospodarce opartej na wiedzy przedsiębiorstwa, aby osiągnąc przewagę konkurencyjną, powinny prowadzić prace badawczo-rozwojowe. Ciągły rozwój procesów lub produktów w firmie jest czasochłonnych oraz kosztownym procesem, jak również wymaga zastosowania specjalistycznej wiedzy. Można zauważyć, że organizacje dążące do uzyskania statusu przedsiębiorstwa opartego na wiedzy inwestują we własne jednostki ba-

\footnotetext{
Małgorzata Śliwa, mgr inż., Uniwersytet Zielonogórski, ul. Licealna 9, Zielona Góra, e-mail: M.Sliwa@iizp.uz.zgora.pl

${ }^{2}$ Justyna Patalas-Maliszewska, dr hab. inż., prof. UZ, Uniwersytet Zielonogórski, ul. Licealna 9, Zielona Góra, tel. 683282 685, e-mail: J.Patalas@iizp.uz.zgora.pl
} 
dawcze. Jednakże należy podkreślić, że przedsiębiorstwa, podejmując decyzję o pozyskaniu nowego rozwiązania, rozpoczynają współpracę z wyspecjalizowanymi jednostkami badawczo-rozwojowymi.

Według Jana Terelaka (2005) kultura organizacyjna przedsiębiorstwa jest spoiwem, które łączy postawy współpracowników, dobra materialne i otoczenie technologiczne ${ }^{3}$. Rafał Kuc i Joanna Moczydłowska (2009) określają kulturę organizacyjną jako aktywność instytucji podejmowaną w realizacji zakładanych celów firmy ${ }^{4}$. Definicję kultury organizacyjnej w przedsiębiorstwie opartym na wiedzy w artykule przyjęto na podstawie tych definicji kultury organizacyjnej i sformułowano jako: „Kultura organizacyjna w przedsiębiorstwie opartym na wiedzy jest przestrzenią, która determinuje postawy pracowników w celu pozyskiwania oraz dzielenia się użyteczną wiedzą w przedsiębiorstwie". Michael Polanyi dokonał jednego z najbardziej upowszechnionych podziałów wiedzy i wyróżnił wiedzę jawną (explicite knowledge), czyli łatwą do pozyskania i zapisu w sposób graficzny, tekstowy lub za pomocą mediów, oraz wiedzę ukrytą (tacit knowledge), czyli trudną do pozyskania i zapisu w sposób sformalizowany ${ }^{5}$.

W artykule poszukuje się zależności pomiędzy kulturą organizacyjną w przedsiębiorstwie opartym na wiedzy a charakterystykami jednostek badawczo-rozwojowych, które są naturalnym źródłem pozyskiwania i kreowania nowej wiedzy, użytecznej dla rozwoju przedsiębiorstwa. Implementacja proponowanego modelu doboru jednostki badawczorozwojowej dla przedsiębiorstwa opartego na wiedzy pozwala na wsparcie procesu decyzyjnego w przedsiębiorstwie $\mathrm{w}$ aspekcie podjęcia współpracy $\mathrm{z}$ jednostką badawczorozwojową.

\section{CHARAKTERYSTYKI KULTURY ORGANIZACYJNEJ W PRZEDSIĘBIOR- STWIE OPARTYM NA WIEDZY}

W literaturze przedmiotu wyróżniono cztery podstawowe grupy elementów budujących kulturę organizacyjną ${ }^{6}$ :

- typ organizacji: sytuacja rynkowa, produkt i technologia, branża, pochodzenie kapitału;

- typ otoczenia: położenie geograficzne, ustrój polityczny, religia, kultura;

- cechy organizacji: wizja, misja, cel, historia, wiek, wielkość, wzorce, struktura;

- cechy uczestników: wiek, płeć, wykształcenie, autorytet, doświadczenie, wzorce zachowań, relacje jednostek i inne.

Zakładając, że kultura organizacyjna w przedsiębiorstwie opartym na wiedzy powinna się przyczyniać do pozyskiwania oraz dzielenia się użyteczną wiedzą wśród pracowników w przedsiębiorstwie, przyjęto na podstawie literatury przedmiotu ${ }^{7}$ mierzalne korzyści wynikające z pozyskiwania oraz dzielenia się wiedzą $\mathrm{w}$ przedsiębiorstwie:

${ }^{3}$ J. Terelak, Psychologia organizacji i zarzadzania, Difin, Warszawa 2005, s. 20.

${ }^{4}$ R. Kuc, J. Moczydłowska, Zachowania organizacyjne, Difin, Warszawa 2009, s. 342-365.

${ }^{5}$ L. Lajtner, M. Śliwa, Atmosfera i kultura pracy w przedsiębiorstwie opartym na wiedzy, [w:] Metody i narzędzia zarzadzania wiedzq $i$ innowacja $w$ przedsiębiorstwach produkcyjnych, red. S. Kłos, J. PatalasMaliszewska, Wydawnictwo Uniwersytetu Zielonogórskiego, Zielona Góra 2014, s. 41-54.

${ }^{6}$ G. Aniszewska, I. Gielnicka, Firma to ja, firma to my, Ośrodek Doradztwa i Doskonalenia Kadr, Gdańsk 1999 , s. 44-57; J. Penc, Kultura i etyka w organizacji. Aspekty pragmatyczne i strategiczne, Wydawnictwo Wyższej Szkoły Policji, Szczytno 2010, s. 64-66.

7 E. Tabaszewska, Nowoczesne koncepcje zarzqdzania - zarzadzanie wiedza, Wydawnictwo Uniwersytetu Ekonomicznego, Wrocław 2008, s. 267. 
- $\quad$ czas opracowania dokumentacji;

- $\quad$ redukcja czasu realizacji projektów;

- redukcja kosztów;

- $\quad$ optymalizacja procesów wewnętrznych;

- $\quad$ zadowolenie klientów;

- $\quad$ redukcja czasu pozyskiwania informacji.

Na podstawie tych definicji dla charakterystyk kultury organizacyjnej według Grażyny Aniszewskiej, Izabeli Gielnickiej ${ }^{8}$, Józefa Penca ${ }^{9}$ oraz Edyty Tabaszewskiej ${ }^{10}$ oraz własnych obserwacji dokonano identyfikacji charakterystyk kultury organizacyjnej dla przedsiębiorstwa opartego na wiedzy:

- mierniki możliwe do określenia w sposób liczbowy:

- liczba osób w zespole,

- stosunek liczby kobiet do mężczyzn (zwany dalej K/M),

- struktura działu (poziomy zależności),

- wiek organizacji,

- przeciętny staż pracy na danym stanowisku,

- poziom wykształcenia (liczba osób z wyższym wykształceniem),

- obroty i przychody firmy;

- mierniki możliwe do określenia za pomocą skali wdrożenia:

- równowaga między życiem prywatnym a zawodowym,

- relacje ze współpracownikami,

- możliwość rozwoju kariery,

- uznanie,

- globalizacja firmy,

- tradycje i wartości.

\section{CHARAKTERYSTYKI JEDNOSTKI BADAWCZO-ROZWOJOWEJ}

Większa konkurencja oraz ciągły rozwój złożonych technologii determinują potrzebę współpracy przedsiębiorstw z jednostkami badawczo-rozwojowymi w celu pozyskania nowej użytecznej wiedzy. W Polsce wyróżniono następujące jednostki badawczorozwojowe ${ }^{11}$ :

- jednostki naukowe i badawczo-rozwojowe:

- placówki naukowe Polskiej Akademii Nauk;

- jednostki badawczo-rozwojowe: jednostki państwowe działające na podstawie ustawy z 25 lipca 1985 r. o jednostkach badawczo-rozwojowych (jednolity tekst DzU $2001 \mathrm{nr} 33$, poz. 388 ze zm.);

- inne: jednostki prywatne, zaklasyfikowane według Polskiej Klasyfikacji Działalności (PKD) 2004 do działu 73 ,Działalność badawczo-rozwojowa”;

- jednostki rozwojowe - podmioty gospodarcze, przede wszystkim przedsiębiorstwa przemysłowe mające własne zaplecze B + R (laboratoria, biura konstrukcyjne, za-

\footnotetext{
${ }^{8}$ G. Aniszewska, I. Gielnicka, op. cit.

${ }^{9}$ J. Penc, op. cit.

${ }^{10}$ E. Tabaszewska, op. cit.

${ }^{11}$ Główny Urząd Statystyczny: Działalność badawcza i rozwojowa $(B+R)$

http://stat.gov.pl/cps/rde/xbcr/wroc/ASSETS_Dzialalnosc_badawcza_i_rozwojowa.pdf, s. 1-2.
} 
kłady rozwoju techniki itp.), prowadzące działalność badawczą i rozwojową głównie o charakterze prac rozwojowych, oprócz swojej podstawowej działalności;

- szkoły wyższe;

- pozostałe jednostki takie jak: szpitale prowadzące prace badawczo-rozwojowe oprócz swojej podstawowej działalności, z wyjątkiem klinik akademii medycznych (uniwersytetów) i Centrum Medycznego Kształcenia Podyplomowego ujętych w kategorii „,szkoły wyższe” oraz szpitali o statusie instytutów naukowo-badawczych ujętych w kategorii ,,jednostki badawczo-rozwojowe".

Współpraca przedsiębiorstwa z jednostkami badawczo-rozwojowymi może przynieść następujące korzyści dla firmy ${ }^{12}$ :

- $\quad$ koncentracja na podstawowym kierunku działania firmy - 72\%;

- oszczędność i obniżka kosztów - 63\%;

- usprawnienie procesu produkcji/świadczenia usługi pod względem jakości, dokładności, czasu itp. - 40\%;

- zmiana sposobu działalności firmy - 35\%;

- $\quad$ rozwój kultury organizacji ukierunkowanej na ciągłe doskonalenie - 32\%;

- dostęp do innowacyjnych rozwiązań organizacyjnych i technicznych - 19\%;

- zdobywanie wiedzy, jaką można wykorzystać w innych obszarach działalności firmy - 19\%;

- zwiększenie zdolności do skutecznego działania w zakresie fuzji i przejęć - 17\%;

- usprawnienie procesu decyzyjnego w całej firmie $15 \%$.

Zakładając, że jednostka badawczo-rozwojowa jest również organizacją, przyjęto charakterystyki kultury organizacyjnej tej jednostki tożsame z przyjętymi dla kultury organizacyjnej w przedsiębiorstwie opartej na wiedzy oraz rozszerzono o dwa dodatkowe parametry:

- procentowa liczba pracowników ze stopniem doktora nauk;

- wartość zaplecza technologicznego (bez infrastruktury).

\section{METODA BADAWCZA}

Model doboru jednostki badawczo-rozwojowej dla przedsiębiorstwa opartego na wiedzy w celu podniesienia poziomu jego kultury organizacyjnej zbudowano przy zastosowaniu równoległej sieci Periego z ograniczona liczbą miejsc. Celem jej stosowania jest zbadanie zależności w organizacji opartej na wiedzy i optymalnego doboru współpracującej z nim instytucji badawczej. Zaproponowana metoda pozwala stwierdzić, czy dana sieć jest ,poprawnie zbudowana" - z reguły właśnie takie sieci odpowiadają poprawnym systemom ${ }^{13}$.

Sformułowano model zależności pomiędzy charakterystykami kultury organizacyjnej w organizacji opartej na wiedzy a parametrami dla jednostki badawczo-rozwojowej na przykładzie przedsiębiorstwa produkcyjnego sektora mikro-, małych i średnich przedsiębiosrtw (MŚP). Określono następujące parametry przedsiębiorstwa produkcyjnego, które zapisano w postaci funkcji:

$$
M(p)=M\left(p_{1}\right)+M\left(p_{2}\right)+\ldots+M\left(p_{17}\right)
$$

\footnotetext{
12 J. Trajer, A. Paszek, S. Iwan, Zarzqdzanie wiedza, Polskie Wydawnictwo Ekonomiczne, Warszawa 2012, s. 39-40.

${ }^{13}$ A. Karatkiewicz, Analiza cyklicznych sieci Petriego przy pomocy dekompozycji blokowej, „Pomiary, Automatyka, Kontrola" 53/5 (2007), s. 69.
} 
gdzie: $M(p)$ - funkcja opisująca przedsiębiorstwo oparte na wiedzy,

$\mathrm{p}_{1}-$ liczba osób w zespole $\leq 10$,

$\mathrm{p}_{2}-$ stosunek liczby kobiet do mężczyzn $(\leq 50 \%)$,

$\mathrm{p}_{3}-$ struktura działu (poziomy zależności) $(\leq 3)$,

$\mathrm{p}_{4}-$ wiek organizacji $(\leq 10)$,

$\mathrm{p}_{5}$ - przeciętny staż pracy na danym stanowisku ( $\geq 3$ lat),

$\mathrm{p}_{6}$ - poziom wykształcenia (ilość os z wyższym wykształceniem) $(\geq 80 \%)$,

$\mathrm{p}_{7}$ - roczne obroty firmy, jak dla $\mathrm{MŚ}^{14}$, czyli nie więcej niż $50 \mathrm{mln}$ euro,

$\mathrm{p}_{8}$ - równowaga $\mathrm{w}$ życiu prywatnym i zawodowym,

$\mathrm{p}_{9}$ - uznanie,

$\mathrm{p}_{10}$ - relacje ze współpracownikami,

$\mathrm{p}_{11}$ - systemy CAD,

$\mathrm{p}_{12}$ - systemy CAM,

$\mathrm{p}_{13}$ - systemy CRM,

$\mathrm{p}_{14}$ - systemy jakości,

$\mathrm{p}_{15}$ - stopień zaawansowania technologii,

$\mathrm{p}_{16}$ - możliwość awansu zawodowego,

$\mathrm{p}_{17}$ - tradycje i wartości.

Parametry $\mathrm{p}_{1}-\mathrm{p}_{7}$ przyjmują wartości mierzalne, natomiast dla parametrów $\mathrm{p}_{8}-\mathrm{p}_{17}$ przyjęto następującą skalę oceny: 1-6 (min.-maks.), gdzie za pozytywny (czyli 1) wynik uważa się oceny 5 i 6, kiedy jest ich więcej niż połowa odpowiedzi wszystkich respondentów, w innym wypadku wynik traktuje się jako negatywny (czyli 0).

W przyjętej metodzie pozycja/tranzycja $(\mathrm{P} / \mathrm{T})$ składa się z uporządkowanej szóstki:

$$
P N=\left(P, T, E, K, W, M_{0}\right)
$$

gdzie: $\mathrm{P}$ - miejsca;

$\mathrm{T}$ - tranzycie;

P i T to niepuste, nieprzecinające się zbiory miejsc i tranzycji;

E - relacje.

$$
\operatorname{dom}(E) \cup \operatorname{cod}(E)=P \cup T
$$

gdzie: $\operatorname{dom}(\mathrm{E})$ - dziedzina;

$\operatorname{cod}(\mathrm{E})$ - przeciwdziedzina.

$$
K: P \rightarrow N
$$

gdzie: $\mathrm{K}$ - funkcja pojemności miejsc,

$\mathrm{N}$ - zbiór liczb naturalnych.

$$
W: E \rightarrow N
$$

gdzie: W - funkcja przepustowości łuków.

$$
M_{0}: P \rightarrow N_{0}
$$

gdzie: $\mathrm{M}_{0}$ - funkcja znakowania początkowego, przy czym: $M_{0}(p) \leq K(p)$ i $\vee p \in P$. Za pionki w siatki przyjęto osoby decyzyjne w firmie. Przykładową strukturę organizacji zestawiono w tabeli 1 .

\footnotetext{
14 Ministerstwo Gospodarki, http://www.mg.gov.pl/Wspieranie+przedsiebiorczosci/Polityki+ przedsiebior-
} czosci+i+innowacyjnosci/Definicja+MSP. 
Tabela 1. Reprezentacyjna struktura organizacji

\begin{tabular}{|l|c|c|}
\hline \multicolumn{1}{|c|}{ Nazwa } & Liczba osób decyzyjnych & Pionek \\
\hline Kierownik magazynu & 1 & $\mathrm{~A}$ \\
\hline Zaopatrzenie & 1 & $\mathrm{~B}$ \\
\hline Dział B+R (tu: badawczo-konstrukcyjny) & 1 & $\mathrm{C}$ \\
\hline Jakość & 2 & $\mathrm{D}$ \\
\hline Planowanie procesu & 1 & $\mathrm{E}$ \\
\hline Produkcja & 2 & $\mathrm{~F}$ \\
\hline Sprzedaż & 1 & $\mathrm{G}$ \\
\hline Prezes & 1 & $\mathrm{H}$ \\
\hline Dyrektor & 1 & $\mathrm{I}$ \\
\hline Kadry & 1 & $\mathrm{~J}$ \\
\hline
\end{tabular}

Źródło: opracowanie własne.

Mając na uwadze zależności występujące w organizacji opartej na wiedzy stworzono sieć Petriego. Ukazuje ona transformacje (prostokąty) składowych oraz ich relacje, które w finalnej fazie kreują kulturę organizacji (rys. 1).

Rys. 1. Sieć Petriego przedstawiająca wpływ poszczególnych relacji z perspektywy działu konstrukcji na kulturę organizacji

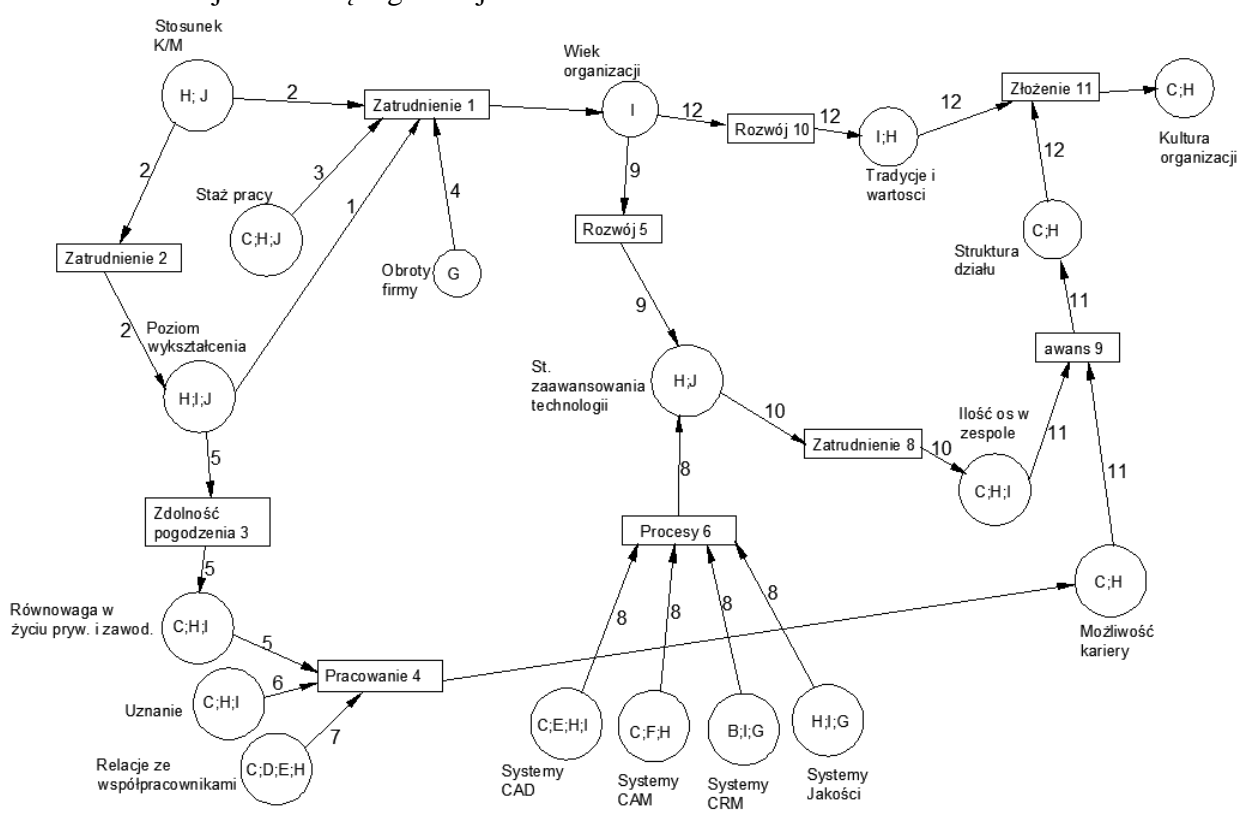

Źródło: opracowanie własne.

Przyjęto następujące założenia (rys. 1): 
1. Przedsiębiorstwa produkcyjne będące na rynku nie dłużej niż 10 lat wykazują tendencję do zatrudniania osób z wyższym wykształceniem.

2. Stosunek kobiet do mężczyzn (K/M) - w przedsiębiorstwie produkcyjnym będącym na rynku nie dłużej niż 10 lat zauważa się, że zatrudnianych jest znacznie więcej mężczyzn niż kobiet, jednakże zatrudniane kobiety podnoszą wskaźnik procentowy udziału osób z wyższym wykształceniem.

3. Przedsiębiorstwa produkcyjne będące na rynku nie dłużej niż 10 lat chętniej zatrudniają osoby z doświadczeniem/stażem na podobnym stanowisku, ponieważ nie mogą sobie pozwolić na zbyt wiele szkoleń w jednym czasie.

4. Stwierdza się, że im większe przychody ma przedsiębiorstwo produkcyjne będące na rynku nie dłużej niż 10 lat, tym bardziej inwestuje w rozwój, czyli skupia większą uwagę na dziale badań i nowych projektach. Rozwija ten obszar, zatrudniając nowych pracowników.

5. Zauważa się, że im wyższy poziom wykształcenia pracowników, tym ciężej osiągnąć równowagę w życiu prywatnym i zawodowym.

6. Uznanie płynące od osób $\mathrm{z}$ bezpośredniego otoczenia (głównie kierownictwo) powoduje efektywniejszą pracę przyczyniającą się do możliwości awansu.

7. Dobre relacje ze współpracownikami i zwierzchnikami przyczyniają się do możliwości rozwoju kariery.

8. Systemy CAD, CAM, CRM, oraz systemy zarządzania jakością, wpływają na bezpośredni rozwój procesów w firmie, tym samym determinują stopień zaawansowania technologii.

9. Im większy wiek organizacji, tym wyższy stopień złożoności procesów i zaawansowania technologii.

10. Stopień zaawansowania technologii (ilość pracy nad produktem) determinuje liczbę potrzebnych osób w zespole.

11. Liczba osób w zespole oraz możliwość kariery pozytywnie wpływają na możliwość awansu i rozbudowują strukturę działu (im więcej osób, im bardziej rozrośnięty zespół, tym większe zróżnicowanie na stanowiska, np. stażysta, młodszy inżynier, inżynier, starszy inżynier, specjalista itp.).

12. Przychody firmy oraz wiek organizacji wpływają na budowanie sieci odbiorców nie tylko na rynku lokalnym, ale i międzynarodowym.

13. Wiek organizacji wpływa na kreacje tradycji i wartości, co łączy się bezpośrednio z kreacją kultury organizacji, podobnie jak struktura analizowanego działu.

Określono również charakterystyki kultury organizacyjnej dla jednostki badawczorozwojowej:

$$
M(r)=M\left(r_{1}\right)+M\left(r_{2}\right)+\ldots+M\left(r_{13}\right)
$$

gdzie: $M(r)$ - funkcja opisująca jednostkę badawczo-rozwojową,

$\mathrm{r}_{1}$ - wiek organizacji $(\geq 6)$,

$\mathrm{r}_{2}$ - przeciętny staż pracy na danym stanowisku ( $\geq 4$ lat),

$\mathrm{r}_{3}$ - procentowa liczba pracowników z stopniem doktora nauk $(>70 \%)$,

$\mathrm{r}_{4}$ - wartość zaplecza technologicznego (bez infrastruktury stałej) (> $3 \mathrm{mln}$ PLN),

$\mathrm{r}_{5}$ - średni wiek kadry,

$\mathrm{r}_{6}$ - zasięg współpracy z kontrahentami (geograficzny, branżowy),

$\mathrm{r}_{7}$ - różnorodność kulturowa kadry pracowniczej, 
$\mathrm{r}_{8}$ - poziom technologiczny realizowanych badań,

$\mathrm{r}_{9}$ - szerokie spektrum badań,

$\mathrm{r}_{10}$ - możliwość rozwoju kariery,

$\mathrm{r}_{11}$ - poziom prestiżu jednostki,

$\mathrm{r}_{12}$ - wartość projektów realizowanych w przemyśle (min. 500 tys. PLN/rok),

$\mathrm{r}_{13}$ - otoczenie gospodarcze.

Parametry $\mathrm{r}_{1}-\mathrm{r}_{5}$ przyjmują wartości mierzalne, natomiast dla parametrów niemierzalnych $\mathrm{r}_{6}-\mathrm{r}_{13}$ przyjęto algorytm oceny podobny jak we wcześniejszym przypadku (tab. 2).

Tabela 2. Reprezentacyjna struktura organizacji badawczo-rozwojowej

\begin{tabular}{|l|c|c|}
\hline \multicolumn{1}{|c|}{ Nazwa } & Liczba osób decyzyjnych & Pionek \\
\hline Doktoranci & $\mathrm{X}$ & $\mathrm{A}$ \\
\hline Adiunkt & $\mathrm{X}$ & $\mathrm{B}$ \\
\hline Profesorzy & $\mathrm{X}$ & $\mathrm{C}$ \\
\hline Kierownik zakładu/katedry & 1 & $\mathrm{D}$ \\
\hline Dyrektor instytutu & 1 & $\mathrm{E}$ \\
\hline Dziekan wydziału & 1 & $\mathrm{~F}$ \\
\hline Rektor & 1 & $\mathrm{G}$ \\
\hline Władze miasta & 1 & $\mathrm{H}$ \\
\hline Przedsiębiorca (prezes) & $\mathrm{X}$ & $\mathrm{I}$ \\
\hline $\begin{array}{l}\text { Kierownik projektu badawczo- } \\
\text { rozwojowego w jednostce }\end{array}$ & 1 & $\mathrm{~J}$ \\
\hline
\end{tabular}

Źródło: opracowanie własne.

Również dla tak przyjętych charakterystyk jednostki badawczo-rozwojowej utworzono sieć Petriego. Ukazuje ona transformacje (prostokąty) składowych oraz ich relacje, które w finalnej fazie stanowią składowe niezbędne do odpowiedniej realizacji projektu prowadzonego na rzecz firmy produkcyjnej (rys. 2). 
Rysunek 2. Sieć Petriego przedstawiająca zależności zachodzące w jednostce badawczorozwojowej

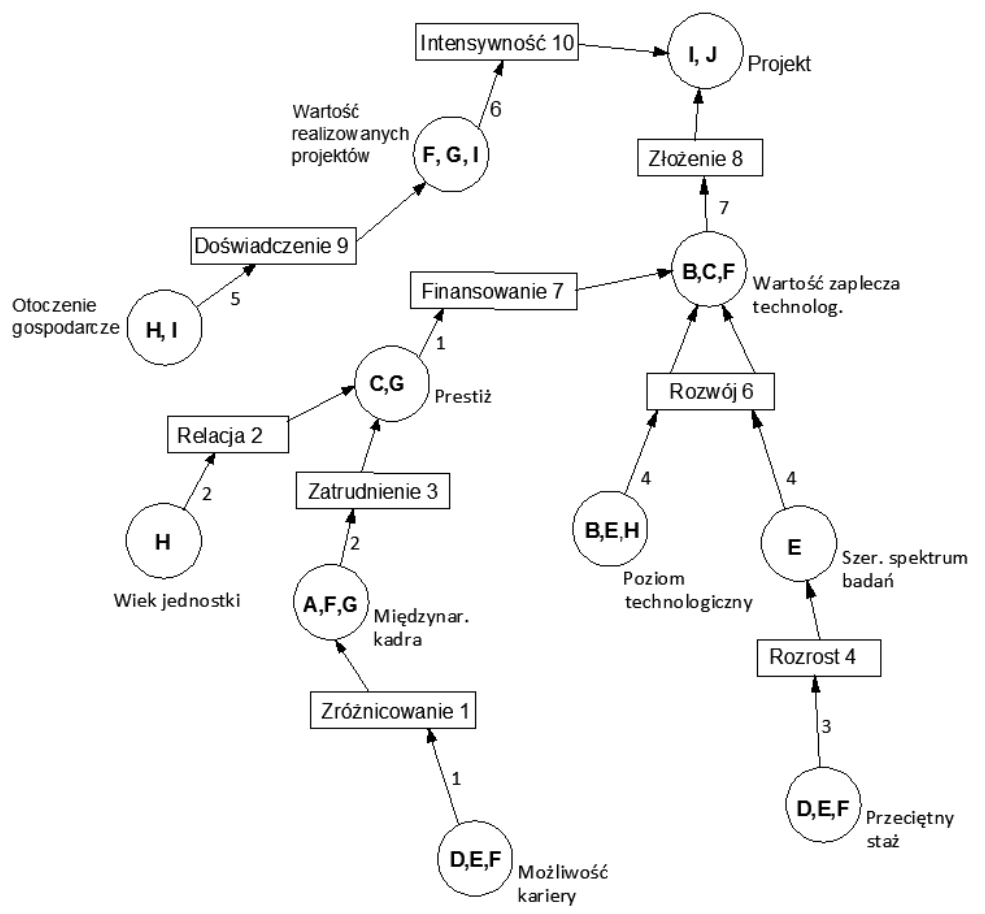

Źródło: opracowanie własne.

Przyjęto następujące założenia (rys. 2):

1. Możliwość rozwoju personalnego w jednostce badawczo-rozwojowej wpływa na zwiększone zainteresowanie naukowców ze środowiska międzynarodowego.

2. Na prestiż jednostki badawczo-rozwojowej wpływa zróżnicowana kadra, ale także wiek jednostki badawczej. Można stwierdzić, że im jednostka badawczorozwojowa starsza, tym większy jej prestiż.

3. Staż pracy naukowca nad danym tematem zwiększa jego umiejętności i czyni specjalistą.

4. Wyższy poziom infrastruktury stosowanej przy prowadzeniu badań wpływa na rozwój jednostki i pozwala na zdobywanie większych grantów i dofinansowania ze źródeł zewnętrznych.

5. Koncentracja działań jednostki badawczo-rozwojowej zależy w dużej mierze od otoczenia gospodarczego (bardziej lub mniej rozwinięty przemysł). Jest to o tyle istotne, ponieważ specyfika i intensywność prowadzenia projektów w środowisku uprzemysłowionym jest dużo większa.

6. Większa wartość projektów realizowanych w przemyśle przez jednostki badawczorozwojowe wpływa na ich prestiż.

7. Na prowadzoną współpracę $\mathrm{z}$ firmami produkcyjnymi wpływa rozwinięte zaplecze technologiczne, a także otoczenie gospodarcze czy staż kadry. 


\section{MODEL DOBORU JEDNOSTKI BADAWCZO-ROZWOJOWEJ DLA PRZED- SIĘBIORSTWA OPARTEGO NA WIEDZY W CELU PODNIESIENIA PO- ZIOMU JEGO KULTURY PRACY}

W aspekcie wyróżnionych korzyści przez Trajera, Paszka oraz Iwana (rozdz. 2) sformułowano autorski model doboru jednostki badawczo-rozwojowej dla przedsiębiorstwa opartego na wiedzy w celu podniesienia poziomu jego kultury pracy przy zastosowaniu sieci Petriego. Przyjęto, że dla zdefiniowanej korzyści dla przedsiębiorstwa ze współpracy z jednostką badawczo-rozwojową: ,dostęp do innowacyjnych rozwiązań organizacyjnych i technicznych”, można podać następujące założenia:

1. Przedsiębiorstwa produkcyjne będące na rynku nie dłużej niż 10 lat chętniej podejmą współpracę $\mathrm{z}$ jednostką badawczo-rozwojową o wyższej wartości zaplecza technologicznego (> 3 mln PLN).

2. Firma $\mathrm{z}$ dużą liczbą pracowników o wyższym wykształceniu ( $\geq 80 \%$ kadry umysłowej) chętniej podejmie współpracę $\mathrm{z}$ jednostka badawczo-rozwojową o wyższej wartości zaplecza technologicznego (> 3 mln PLN).

3. Pracownicy ze stażem większym niż 4 lata pracy na podobnym stanowisku chętniej współpracują z jednostką badawczo-rozwojową o wyższej wartości zaplecza technologicznego.

4. Im większe obroty roczne firmy (ale $\leq 5 \mathrm{mln} €$ ), tym chętniej jest podejmowana współpraca $\mathrm{z}$ jednostką badawczo-rozwojową o wyższej wartości zaplecza technologicznego.

5. Firma w środowisku konkurencyjnym ( $\mathrm{z}$ zaawansowanymi systemami CAD, CAM, CRM, systemy jakości), chętniej podejmie współpracę z jednostką badawczo-rozwojową osadzoną w strefie gospodarczej i współpracującą przy projektach realizowanych w przemyśle.

Zależności 1-4 będą występowały z apostrofem, na przykład: 1', 2'..., w kontekście całości, jako że odnoszą się do podobnego rodzaju relacji oznaczone zostaną jako 6', natomiast zależność 5 zostanie określona dla ułatwienia jako 5'.

Powiązania w poszczególnych elementach sieci na rysunku 3 (także na rys. 4) oparto na sieciach z rysunków 1 i 2 . Występujące tam charakterystyki oraz pionki pozostały bez zmian. Dla lepszej widoczności wyróżniono:

- kolorem niebieskim - elementy przynależące do przedsiębiorstwa opartego na wiedzy,

- kolorem czarnym - elementy jednostki naukowej,

- czerwonym - nowo powstałe zależności. 
Rys. 3. Sieć Petriego przedstawiająca zależności wpływające dobór jednostki badawczorozwojowej ze względu na dostęp do innowacyjnych rozwiązań organizacyjnych i technicznych

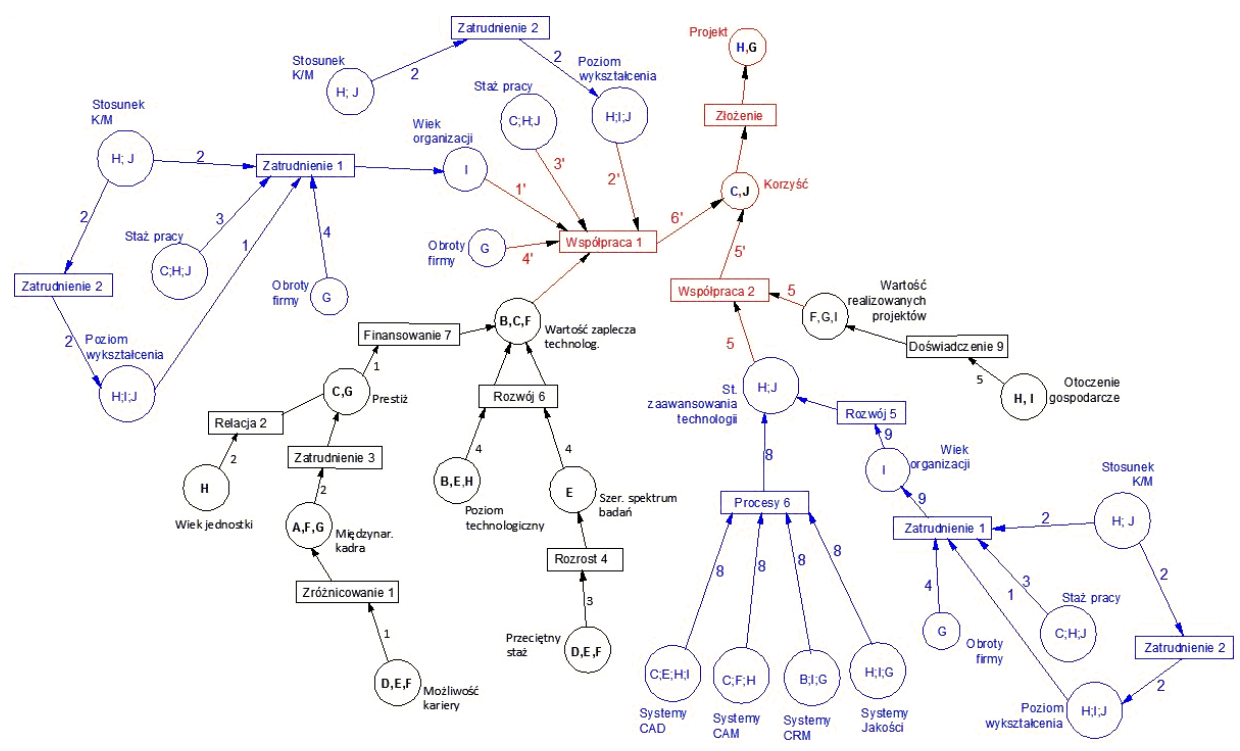

Źródło: opracowanie własne.

Dla zdefiniowanej korzyści dla przedsiębiorstwa ze współpracy z jednostką badawczorozwojową: „rozwój kultury organizacji ukierunkowanej na ciągłe doskonalenie”, można podać następujące założenia:

1. Firma ceniąca wartości i tradycje oraz będąca na rynku nie dłużej niż 10 lat chętniej podejmie współpracę $\mathrm{z}$ jednostką badawczo-rozwojową o większym prestiżu.

2. Firma, w której dużą uwagę przywiązuje się do zapewnienia właściwej jakości produktów, chętniej nawiąże współpracę z doświadczonym ośrodkiem badawczorozwojowym, dysponującym szerokim zakresem badań.

3. Pracownicy przedsiębiorstwa $\mathrm{z}$ wyższym wykształceniem są otwarci na nowe rozwiązania i chętniej nawiązują kontakt $\mathrm{z}$ jednostką badawczo-rozwojową zatrudniającą również pracowników zagranicznych.

4. Pracownik, który upatruje możliwość kariery w przedsiębiorstwie, intensywnie poszukuje rozwiązań i chętniej podejmie współpracę $\mathrm{z}$ jednostką badawczorozwojową.

5. Przedsiębiorstwa produkcyjne będące na rynku nie dłużej niż 10 lat starają się dopiero zbudować markę, więc są otwarte na nowe propozycje i doskonalenie. Chętniej zlecają analizę procesów jednostkom badawczo-rozwojowym, które aktywnie realizują projekty w przemyśle (doświadczenie). 
Rys. 4. Sieć Petriego przedstawiająca zależności wpływające na rozwój kultury organizacji ukierunkowanej na ciągłe doskonalenie

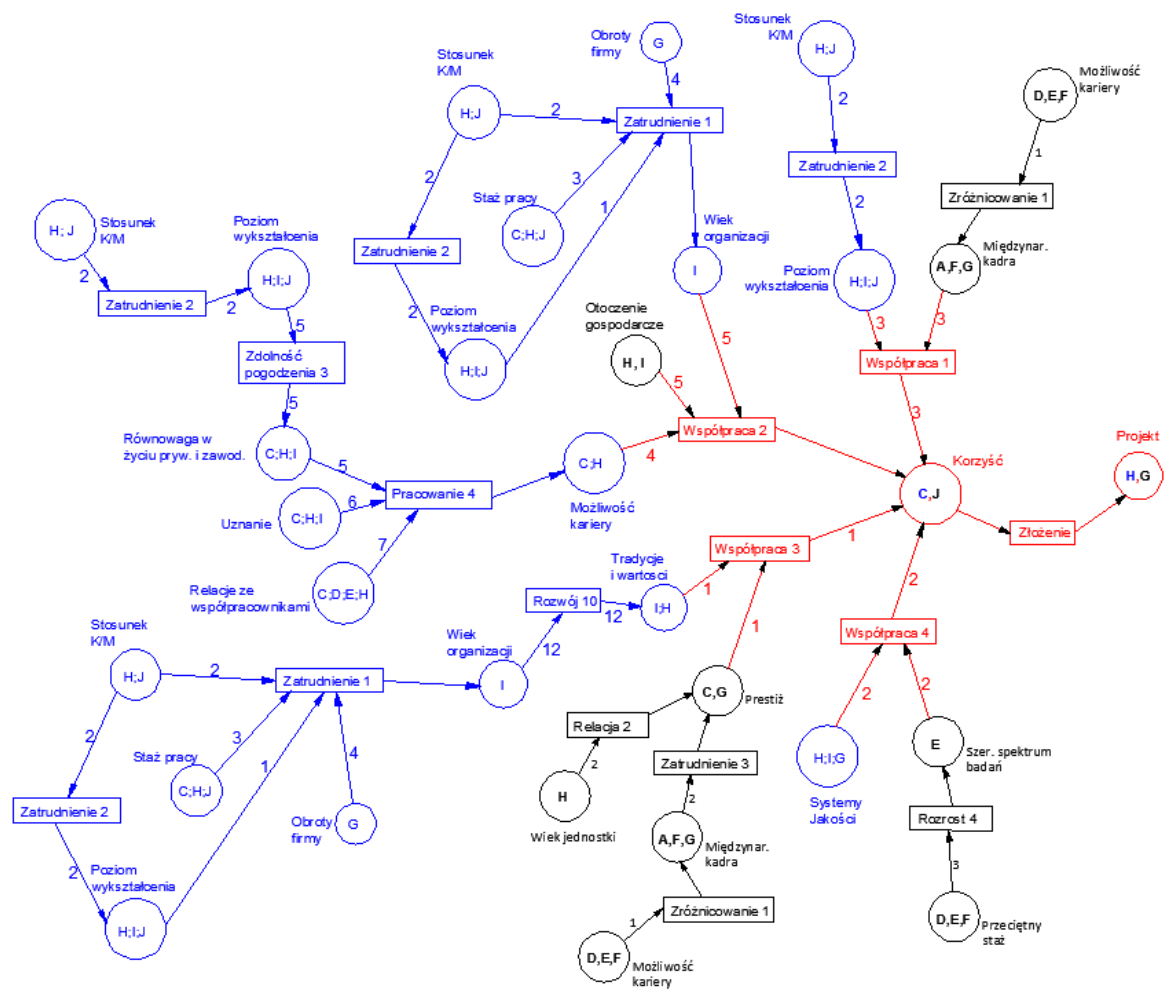

Źródło: opracowanie własne.

Proponowane modele doboru jednostki badawczo-rozwojowej dla przedsiębiorstwa opartego na wiedzy przy zastosowaniu sieci Petriego zostały sformułowane na podstawie analizy literatury przedmiotu oraz własnych obserwacji. Implementacja zaproponowanych modeli pozwoli przedsiębiorstwu na osiągnięcie korzyści w postaci ciągłego doskonalenia organizacji lub zwiększenia dostępu do innowacyjnych rozwiązań organizacyjnych i technicznych.

\section{WNIOSKI}

Problem doboru jednostki badawczo-rozwojowej dla przedsiębiorstwa w celu pozyskania użytecznej wiedzy dla potrzeb tworzenia i pozyskania nowych rozwiązań jest zagadnieniem szczególnie ważnym w gospodarce opartej na wiedzy. Na podstawie wskazanych relacji, dzięki zastosowaniu sieci Petriego, zbudowano modele doboru jednostki badawczo-rozwojowej dla przedsiębiorstwa opartego na wiedzy w kontekście osiągnięcia przez organizację określonych korzyści. Implementacja proponowanych modeli doboru jednostki badawczo-rozwojowej dla przedsiębiorstwa opartego na wiedzy przy zastosowaniu sieci Petriego, między innymi w instytucjach okołobiznesowych, których zadaniem 
jest wspieranie wdrażania innowacji w przedsiębiorstwach oraz wymiany wiedzy w tym zakresie $^{15}$, może umożliwić efektywne wykorzystanie osiągnięć nauki dla potrzeb praktyki gospodarczej. Na przykładzie modelu przy zastosowaniu sieci Petriego przedstawiającego zależności wpływające na rozwój kultury organizacji ukierunkowanej na ciągłe doskonalenie, dzięki wiedzy, że przedsiębiorstwa chętniej nawiązują kontakt z jednostką badawczo-rozwojową zatrudniającą również pracowników zagranicznych, należy podjąć działania służące zwiększeniu zatrudnienia w danej jednostce pracowników zagranicznych. Również na podstawie sformułowanego modelu dzięki informacji, że przedsiębiorstwa chętniej podejmą współpracę z jednostką badawczo-rozwojową, która aktywnie realizuje projekty $\mathrm{w}$ przemyśle, powinno się podjąć działania w jednostce badawczorozwojowej dążące do promowania tej aktywności. Ponadto wydaje się, że korzystne dla jednostek badawczo-rozwojowych byłoby wykorzystanie wiedzy o zależnościach, jakie występują pomiędzy kulturą organizacyjną w przedsiębiorstwach opartych na wiedzy a jednostkami badawczo-rozwojowymi, pokazanymi na modelach przy zastosowaniu sieci Petriego. Dalsze badania autorów koncentrują się na weryfikacji proponowanych modeli w rzeczywistości gospodarczej.

\section{LITERATURA}

[1] Aniszewska G., Gielnicka I., Firma to ja, firma to my, Ośrodek Doradztwa i Doskonalenia Kadr, Gdańsk 1999.

[2] Jashapara A., Zarzadzanie wiedzq, Polskie Wydawnictwo Ekonomiczne, Warszawa 2004.

[3] Karatkiewicz A., Analiza cyklicznych sieci Petriego przy pomocy dekompozycji blokowej, „Pomiary, Automatyka, Kontrola” 53/5 (2007), s. 69-71.

[4] Koźmiński A.K., Jemielniak D., Zarzadzanie od podstaw, Wydawnictwo Akademickie i Profesjonalne, Warszawa 2009.

[5] Kuc R., Moczydłowska J., Zachowania organizacyjne, Difin, Warszawa 2009.

[6] Lajtner L., Śliwa M., Atmosfera i kultura pracy w przedsiębiorstwie opartym na wiedzy, [w:] Metody i narzędzia zarzadzania wiedza i innowacja $w$ przedsiębiorstwach produkcyjnych, red. S. Kłos, J. Patalas-Maliszewska, Wydawnictwo Uniwersytetu Zielonogórskiego, Zielona Góra 2014, s. 41-54.

[7] Patalas-Maliszewska J., Woźniak W., Model transferu myśli innowacyjnej na przyktadzie województwa lubuskiego, [w:] Jakość, innowacyjność i transfer technologii w rozwoju przedsiębiorstw - INTELTRANS 2006, IV konferencja naukowo-techniczna, Kraków 2006, s. 143-150.

[8] Penc J., Kultura i etyka w organizacji. Aspekty pragmatyczne i strategiczne, Wydawnictwo Wyższej Szkoły Policji, Szczytno 2010.

[9] Perechuda K., Zarządzanie wiedza w przedsiębiorstwie, PWN, Warszawa 2005.

[10] Prudzienica M., Zarzadzanie wiedza $w$ kreowaniu innowacji zarzadczych, Wydawnictwo Uniwersytetu Ekonomicznego we Wrocławiu, Wrocław 2011.

[11] Senge P., Leading Learning Organizations: the bold, the powerful \& the invisible, The Leader of the Future, Jossey-Bass, San Francisco 1996.

[12] Sosnowska A., Formy powiazań sfery $B+R$ ze sfera produkcji, [w:] Sfera badawczorozwojowa i przedsiębiorstwa $w$ działalności innowacyjnej, red. K. Poznańska, Oficyna Wydawnicza SGH, Warszawa 2001, s. 10-11.

[13] Steinmann H., Schreyogg G., Zarzadzanie. Podstawy kierowania przedsiębiorstwem. Koncepcje, funkcje, przyktady, Oficyna Wydawnictwo Politechniki Wrocławskiej, Wrocław 1998.

\footnotetext{
${ }^{15}$ J. Patalas-Maliszewska, W. Woźniak, Model transferu myśli innowacyjnej na przyktadzie województwa lubuskiego, [w:] Jakość, innowacyjność i transfer technologii w rozwoju przedsiębiorstw - INTELTRANS 2006, IV konferencja naukowo-techniczna, Kraków 2006, s. 143-150.
} 
[14] Szopik K., Działalność Badawczo-Rozwojowa w Polsce, „Zeszyty Naukowe Uniwersytetu Szczecińskiego" 2007/8, s. 285-294.

[15] Tabaszewska E., Nowoczesne koncepcje zarzadzania - zarzadzanie wiedza, Wydawnictwo Uniwersytetu Ekonomicznego, Wrocław 2008.

[16] Terelak J., Psychologia organizacji i zarzadzania, Difin, Warszawa 2005.

[17] Trajer J., Paszek A., Iwan S., Zarzadzanie wiedza, Polskie Wydawnictwo Ekonomiczne, Warszawa 2012.

\section{Źródła internetowe}

[1] Ministerstwo Gospodarki, Definicja MŚP, http://www.mg.gov.pl/Wspieranie+przedsiebiorczosci/Polityki+przedsiebiorczosci+i+innowac yjnosci/Definicja+MSP (dostęp: 5.09.2015).

[2] Kijeńska I., Działalność innowacyjna jednostek badawczo-rozwojowych, uczelni wyższych i instytutów Polskiej Akademii Nauk sektora nauk technicznych http://www.instytut.info/IIIkonf/referaty/3b/IzabelaKijenska_dzialalnosc\%20innowacyjna\%20 jenostek\%20badawczo_rozwojowych.pdf (dostęp: 20.03.2015).

[3] Główny Urząd Statystyczny, Działalność badawcza i rozwojowa $(B+R)$ http://stat.gov.pl/ cps/rde/xbcr/wroc/ASSETS_Dzialalnosc_badawcza_i_rozwojowa.pdf (dostęp: 28.02.2015).

[4] KPMG, Działalność badawcza i rozwojowa w Polsce w 2020 roku, http://www.kpmg.com/pl/pl/issuesandinsights/articlespublications/strony/dzialalnoscbadawcza-i-rozwojowa-w-polsce-w-2020-roku.aspx (dostęp: 18.03.2015).

\section{SELECTION MODEL OF A RESEARCH AND DEVELOPMENT INSTITUTE FOR A KNOWLEDGE-BASED COMPANY}

In the knowledge-based economy, enterprises should cooperate with research and development institutes. An organizational culture in a knowledge-based organization can be created by the dynamics of the market, the need of improving of innovation implementation (of technology, product) to achieve a competitive advantage. The definition of an organizational culture in a knowledge-based company is based on the definition by J. Terelak (2005) and R. J. Kuc and Moczydłowska (2009). It is formulated as a space in the enterprise, that determines attitude of the workers in term of acquiring and sharing an useful tacit and explicit knowledge in an enterprise. In the article is formulated the selection model of a research and development institute for a knowledge-based company in term of enhancing of the level of organization culture. Based on the literature studies, authors define the characteristics of organization culture in the knowledge-based enterprise and parameters for the research and development institute. Meters that define these relationships describe culture of both institutions, working environment, technology and employee development. By implementing the method of Petri -net (with limited capacity and number of seats) selection model of a research and development institute for a knowledge-based company is defined. This model supports decisionmaking process in the enterprise in the aspect of cooperating with the R\&D institute and realizing a joint research and development project. Based on own research and observations two connected Petri nets were defined. The implementation of research results should provide to improving of level of organization culture in the knowledge-based organization.

Keywords: an organization culture, research and development institute, explicit knowledge, tacit knowledge

DOI: 10.7862/rz.2015.mmr.49

Tekst złożono w redakcji: wrzesień 2015

Przyjęto do druku: październik 2015 